Marquette University

e-Publications@Marquette

College of Nursing Faculty Research and

Publications

Nursing, College of

$1-1-2017$

\title{
Development and Psychometric Evaluation of the Nurses Professional Values Scale-3
}

Darlene Weis

Marquette University, darlene.weis@marquette.edu

Mary Jane Schank

Marquette University, maryjane.schank@marquette.edu

Accepted version. Journal of Nursing Measurement, Vol. 25, No. 3 (2017): 400-410. DOI. (C) 2017 Springer Publishing Company. Used with permission. 
Marquette University

\section{e-Publications@Marquette}

\section{Nursing Faculty Research and Publications/College of Nursing}

This paper is NOT THE PUBLISHED VERSION; but the author's final, peer-reviewed manuscript.

The published version may be accessed by following the link in the citation below.

Journal of Nursing Measurement, Vol. 25, No. 3 (2017): 400-410. DOI. This article is (C) Springer and permission has been granted for this version to appear in e-Publications@Marquette. Springer does not grant permission for this article to be further copied/distributed or hosted elsewhere without the express permission from Springer.

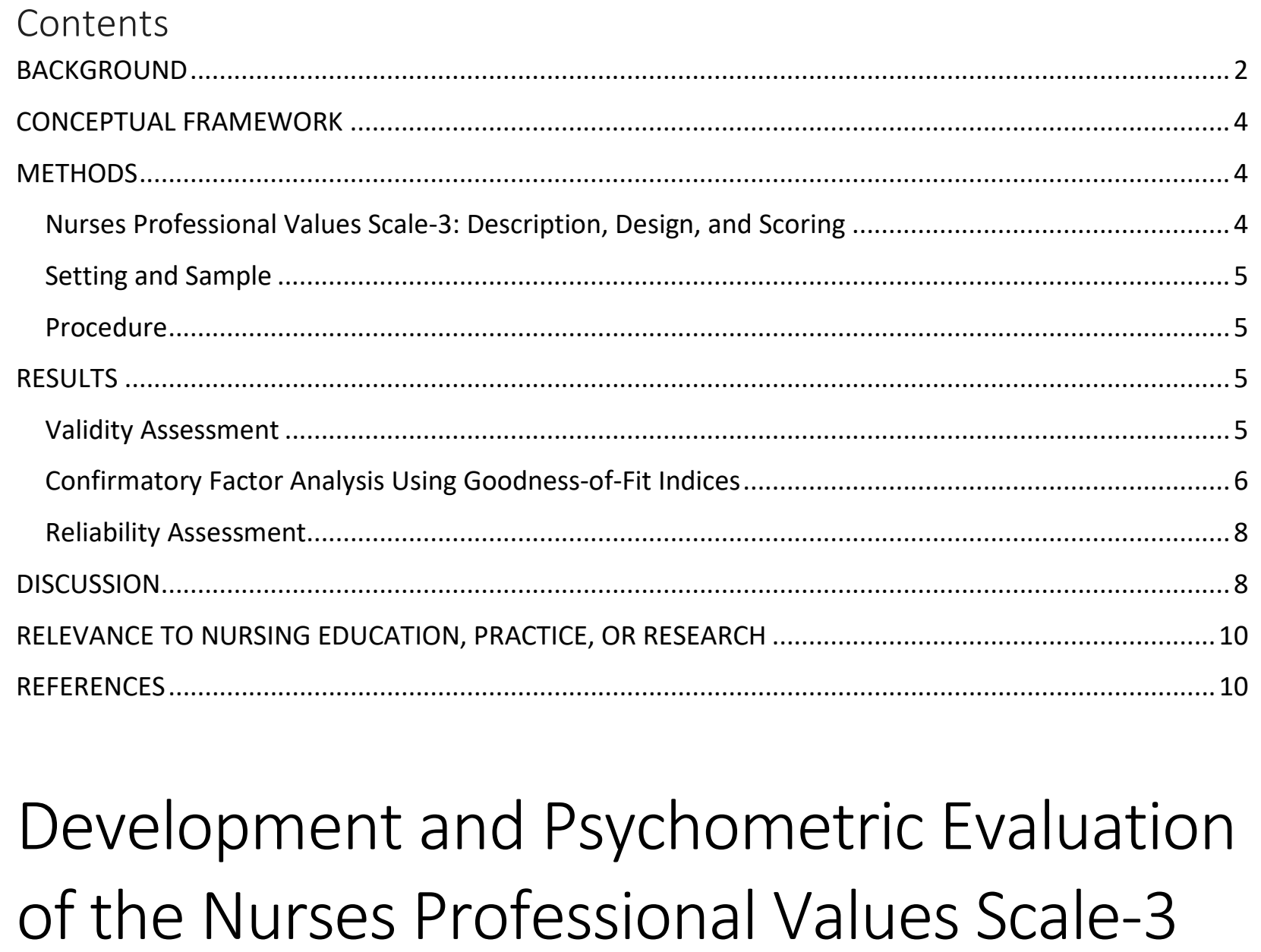




\section{Darlene Weis}

Marquette University College of Nursing, Milwaukee, WI

\section{Mary Jane Schank}

Marquette University College of Nursing, Milwaukee, WI

\section{Abstract}

Background and Purpose: The Nurses Professional Values Scale-3 (NPVS-3) is an instrument derived from the American Nurses Association Code designed to measure nurses' professional values. The purpose of this study was to examine its psychometric properties. Methods: A random sample of 1,139 baccalaureate nursing students, graduate nursing students, and practicing nurses participated. The 28-item Likert-scale instrument was subjected to exploratory and confirmatory factor analysis. Principal components analysis with varimax rotation and Kaiser normalization resulted in a 3-factor solution. Results: Findings supported internal consistency reliability of 3 factors with alpha coefficients from .80 to .91 and total scale coefficient of .94 . Construct validity was supported with a factor loading range of .31-.95 across 3 factors-Caring, Activism, Professionalism. Conclusion: NPVS-3 is a psychometrically sound instrument that can be used by nursing researchers, educators, administrators, and practitioners.

Keywords: professional values; instrument development; values development; Code of Ethics for Nurses

In an era of increasing globalization, diversity, and health disparities, a myriad of new and continuing ethical dilemmas in health will challenge professional values. Ongoing transformation of the health care system as well as the need to maintain safe, high-quality care give impetus to value-driven decisions. Values associated with professional practice have never been more crucial to nursing. The values espoused by the profession need to be brought to the forefront of organizational decision making (Weis, 1995). The acquisition and internalization of values espoused by the profession are central to professional development and provide for a common framework on which expectations and standards can be developed. They are standards for action preferred by practitioners and the profession and can be used to evaluate the integrity of the individual and the organization. The Nurses Professional Values Scale-3 (NPVS-3) is an instrument that can be used in nursing education and across the myriad of nursing practice settings to ascertain the development and sustainability of professional values. The purpose of this article is to describe the NPVS-3, its development, and the validity and reliability of the instrument. The NPVS-3 is a revision of the NPVS-Revised (NPVS-R; 2009), which was necessitated by the changes to the American Nurses Association (ANA, 2015) Code of Ethics for Nurses With Interpretive Statements.

\section{BACKGROUND}

Concerns regarding the development of professional values are evident in the writing of numerous authors (Çelik \& Hisar, 2012; Forbes \& Hickey, 2009; Ham, 2004; Irving \& Snider, 2002; Leners, Rohrs, \& Piccone, 2006; Milton, 2003; Sellman, 2011). The importance of values and values education continue to be affirmed in nursing with the updated publication The Essentials of Baccalaureate Education for Professional Nursing Practice, in which values fundamental to baccalaureate nursing education were identified (American Association of Colleges of Nursing [AACN], 2008). As noted in the AACN document, "professional values and their associated behaviors are foundational to the practice of nursing" (AACN, 2008, p. 26). Forbes and Hickey (2009) point out the 
importance of integrating professional values into the curriculum. Specifically, they note integration of values in all nursing courses, "with values education an identified core competency," (Forbes \& Hickey, 2009 , p. 8) is necessary. However, according to Irving and Snider (2002), the values that have been associated with excellence in practice are beginning to be viewed as "nice to know," that is, not required. Value development, the ability to deal with issues of right and wrong, is perceived as less important than mastery of facts. Ham (2004) indicated that environmental factors may over time erode a nurse's commitment to codes of right and wrong. Sellman (2011) argued that values need a secure foundation if they are to survive in a health care system in which the managerial imperative and technology with its focus on effectiveness are the dominant forces.

The original NPVS was based on the 1985 ANA Code of Ethics for Nurses With Interpretive Statements (Weis \& Schank, 2000). This version of the Code of Ethics had 11 statements. As noted in this version of the Code of Ethics, the first six statements pertain to nurses' responsibility to "clients." The last five statements focus on the social nature of the profession and its responsibility to the public through policy and political activity. In the 1985 Code of Ethics, the nurse as "caregiver" was emphasized. This reflects the historical and traditional image of nurses as "hands-on" providers of care. In addition, the arena of practice was limited.

In the 2001 Code of Ethics, nine provisions (the new name for statements) were delineated. This revision of the Code of Ethics noted that the first three provisions describe the fundamental values and commitments of the nurse. The next three address duty and loyalty of the nurse. The last three focus on the social nature of the profession and its responsibility to the public. These three provisions as well as the last five statements in the 1985 Code of Ethics had policy and political implications that required the individual nurse, as well as the collective professional body, to become proactively involved in health care policy. The 2001 Code of Ethics uses the term patient, whereas the 1985 Code of Ethics uses the term client. In the 2001 Code of Ethics revision, patient is used in the broadest context, inclusive of all recipients of care for health or illness in health care facilities or community settings. Similarly, practice refers to whatever role the nurse fulfills, for example, health care provider, educator, administrator, or researcher. The changes from 1985 to 2001 show the expansive nature as well as the changing role of the nurse in society.

In the 2015 Code of Ethics, nine provisions were again delineated with revisions. This Code of Ethics revision noted that the first three provisions again focus on the fundamental values and commitments of the nurse. However, the nature of health rather than health problems becomes a focus in the 2015 Code of Ethics. In addition, the role of the nurse was expanded to include populations as well as expanded responsibility in patient health and safety. The next three provisions emphasize the boundaries of duty and loyalty the same as in the 2001 Code of Ethics. However, the focus becomes one of increasing authority and leadership in promoting health, including personal health and providing optimal care. Also, there is a shift in emphasis placed on the environment and ethical obligation. The final three provisions focus on the social nature of the profession and its responsibility to the public while at the same time stressing not only the global nature of nursing but also the need for nursing to be proactive in global health. These provisions speak to the need for the individual nurse, as well the profession as a whole, to impact health policy. In the latest Code of Ethics revision, the terms patient and client are both used. The changes from 2001 to 2015 show the ever-expanding role of the nurse and shifting boundaries of nursing, specifically in the areas of human rights, health diplomacy, and global 
health. The NPVS, NPVS-R, and the NPVS-3 are the only known instruments that measure professional nursing values based on the ANA Code of Ethics for Nurses.

\section{CONCEPTUAL FRAMEWORK}

The NPVS and NPVS-R were conceptualized based on a critical review of literature pertaining to the Code of Ethics (ANA, 1985, 2001), values (Krathwohl, Bloom, \& Masia, 1964; Raths, Harmin, \& Simon, 1966), and professional values development in nurses (Eddy, Elfrink, Weis, \& Schank, 1994; Lutz, Elfrink, \& Eddy, 1991; O'Neill, 1973; Packard \& Ferrara, 1988; Partridge, 1978; Strasen, 1989; Thurston, Flood, Shupe, \& Gerald, 1989). Since the review and publication of the NPVS-R, additional writings on professional values development have been published (Cooper, 2009; Ham, 2004; Irving \& Snider, 2002; LeDuc \& Kotzer, 2009; Leners et al., 2006; Lui et al., 2008; Martin, Yarbrough, \& Alfred, 2003; McNeese-

Smith \& Crook, 2003; Milton, 2003; Rassin, 2008; Schank \& Weis, 2001; Shih et al., 2009; Weis \& Schank, 2002). Lin, Wang, Yarbrough, Alfred, and Martin (2010) state that Codes of Ethics have provided the frameworks used by nursing faculty to introduce students to the values of the nursing profession.

Nursing's professional values are articulated in the ANA Code of Ethics for Nurses (ANA, 2015), the ANA's Nursing's Social Policy Statement (ANA, 2010), The Essentials of Master's Education in Nursing (AACN, 2011), Essentials of Doctoral Education for Advanced Nursing Practice (AACN, 2006), Implementing Health Care Reform: Issues for Nursing (American Academy of Nursing, 2010), and Standards for Clinical Nursing (ANA, 1998). Regardless of the practice setting, these value documents influence nursing activity and the development of nursing as a profession. The Code of Ethics for Nurses provides direction for relationships of nurses to patients, the community, and the profession. It is expected that nurses "adhere to the ideals and moral norms of the profession . . to embrace them as part of what it means to be a nurse" (ANA, 2015, p. 15).

Thorpe and Loo (2003) point out that the adoption of professional values occurs within educational programs. Forbes and Hickey (2009) also stress the importance of professional values education. Specifically, they note integration of values throughout all nursing courses, "with values education an identified core competency of the program," (p. 8) is necessary. That values are essential for developing and sustaining a professional identity and crucial to professional practice are evident in the writings of these as well as the other authors previously noted.

\section{METHODS}

\section{Nurses Professional Values Scale-3: Description, Design, and Scoring}

Methods used in the NPVS-R instrument development were incorporated into the design and testing of the NPVS-3. The NPVS-3 is a 28-item instrument with a Likert-scale format ranging from 1 (not important) to 5 (most important). Each item in the NPVS-3 is a short descriptive phrase reflecting a specific code provision and its interpretive commentary. All items are phrased in the positive direction; none are reverse scored. The possible range of scores is $28-140$. The higher the score, the stronger the nurse's professional value orientation. Total scores are obtained by summing numeric responses to each item. The NPVS-3 does not have subscales nor did the NPVS and NPVS-R because the Code of Ethics for Nurses is conceptualized as a single entity.

The NPVS-3 was given to three judges with expertise in the Code of Ethics for Nurses to establish content validity. These experts included nurse educators and nurse practitioners who have published, 
taught, and been involved with revision of the Code of Ethics for Nurses. The revised instrument was reviewed individually by the judges for item-to-item relevance and sufficiency to the nine code provisions with interpretive statements, readability, clarity, and meaning. Their review resulted in general agreement, with some wording changes. The NPVS-3 instrument consists of 15 items unchanged from the NPVS-R instrument, 5 revised items and 8 new items. The revisions were necessitated by changes to the Code of Ethics for Nurses (ANA, 2015).

\section{Setting and Sample}

There were 1,139 participants, including baccalaureate nursing students (n 5243 ), graduate nursing students (n 5 237), and practicing nurses (n 5 659), who completed the NPVS-3. The students were enrolled in nursing programs selected at random from the Commission on Collegiate Nursing Education. The practicing nurses were self-selected from a major health care system.

The study sample was $94 \%$ female. The ethnicity of the respondents is as follows: White (92.9\%), African Americans (2.0\%), Asian/Pacific Islander (2.6\%), Hispanic (1.6\%), and Native Americans (0.9\%).

\section{Procedure}

Data were managed and analyzed using the SPSS Version 22 and AMOS Version 22. The responses of the participants to the NPVS-3 were randomly split and subjected to principal components analysis (PCA) with varimax rotation and Kaiser normalization. PCA with varimax rotation was selected, as the factors were not thought to be correlated with each other in this Code of Ethics. This rotation helps to maximize factor loadings of each item on one factor, thereby clarifying the relationship of each item to a particular factor (Ferketich \& Muller, 1990). Internal consistency reliability of the total instrument was examined using Cronbach's alpha procedure. Construct validity was assessed by conducting a confirmatory factor analysis (CFA) with maximum likelihood estimation to determine if the data collected from this study sample were consistent with the theoretical basis of the instrument (Bentler, 1997). CFA approaches examine whether existing data are consistent with a highly constrained a priori structure that meets conditions of model identification.

\section{RESULTS}

\section{Validity Assessment}

Validity assessment of the NPVS-3 was examined using factor analysis. The KaiserMeyer-Olkin measure of sampling adequacy was .96 , and the Bartlett's test of sphericity was statistically significant ( $p$ $<.000$ ), indicating sample adequacy (Field, 2000; Strickland, 2003).

Several a priori rules were used to determine the number of factors in the PCA solution: (a) Only those factors with an eigenvalue of 1 or greater were retained; (b) Cattell's (1978) scree test, in which retained factors are those above the point where the scree plot flattens out; and (c) the result makes theoretical sense (Nunnally \& Bernstein, 1994). A minimum factor loading of .30 was used as criterion for each retained item (Meyers, Gamst, \& Guarino, 2006). Using these criteria, three factors were identified. These factors explained $51.62 \%$ of the extracted common variance (Table 1 ).

Factor 1 had an eigenvalue of 11.98 and accounted for $39.9 \%$ of the variance. Ten items loaded on this factor, labeled Caring. In these items, the focus is on commitment to the patient whether 
individual, family, group, community, or population. Factor 2, with an eigenvalue of 2.33, accounted for $7.8 \%$ of the variance. Ten items loaded on this factor, named Activism. The items in this factor focus on the dynamic component of the profession through which nursing and the nurse at all levels can impact health policy, promote health diplomacy, and maintain integrity of the profession. Factor 3 had an eigenvalue of 1.17, accounting for 3.9\% of the variance. This factor, called Professionalism, had an eight items loading. This factor reflects the responsibility for the work environment, for personal and professional growth, as well as authority and responsibility for practice.

\section{Confirmatory Factor Analysis Using Goodness-of-Fit Indices}

CFA supported the a priori hypothesis that the NPVS-3 consisted of three factors: Caring, Activism, and Professionalism. The CFA resulted in the deletion of one variable in Factor 3 because of low regression weight (Meyers et al., 2006). Figure 1 denotes the relationship of the 28 observed variables to the three content variables.

This model generated the following goodness-of-fit indices: root mean square error of approximation (RMSEA) 5.065 (,.08 indicates an "acceptable fit"), comparative fit index (CFI) 5.90 (..90 is desirable), and goodness-of-fit index (GFI) 5.875 (..90 is desirable). The indices indicated adequacy of fit (Hu \& Bentler, 1999; Meyers et al., 2006). These indices are not robust, indicating that further study of the model is needed. 
TABLE 1. Exploratory Principal Components Analysis Factor Loadings for the Nurses Professional Values Scale-3

\begin{tabular}{|c|c|c|}
\hline Item & $N=1,139 ;$ Scale Cronbach's alpha -.944 & \\
\hline \multicolumn{3}{|c|}{ Factor 1: Caring ( $39.9 \%$ variance, Cronbach's alpha $=.885$ ) } \\
\hline 15 & Protect moral and legal rights of patients & .79 \\
\hline 18 & Provide care without bias or prejudice to patients and populations & .78 \\
\hline 19 & Safeguard patient's right to confidentiality and privacy & .78 \\
\hline 2 & Respect the inherent dignity, values, and human rights of individuals & .67 \\
\hline 3 & Protect health and safety of the patient/public & .65 \\
\hline 22 & Practice guided by principles of fidelity and respect for person & .65 \\
\hline 16 & Act as a patient advocate & .59 \\
\hline 14 & Accept responsibility and accountability for own practice & .51 \\
\hline 21 & Protect rights of participants in research & .36 \\
\hline 20 & Confront practitioners with questionable or inappropriate practice & .33 \\
\hline \multicolumn{3}{|c|}{ Factor 2: Activism ( $7.8 \%$ variance, Cronbach's alpha $=.912)$} \\
\hline 24 & Participate in professional efforts to advance global health & .95 \\
\hline 23 & Actively promote health of populations & .77 \\
\hline 26 & $\begin{array}{l}\text { Take action to influence legislators and other policy makers to } \\
\text { improve health care }\end{array}$ & .70 \\
\hline 12 & Establish collaborative partnerships to reduce health care disparities & .63 \\
\hline 13 & Assume responsibility for meeting health needs of diverse populations & .60 \\
\hline 11 & $\begin{array}{l}\text { Recognize the role of professional nursing associations in shaping } \\
\text { health policy }\end{array}$ & .59 \\
\hline 10 & $\begin{array}{l}\text { Advance the profession through active involvement in health-related } \\
\text { activities }\end{array}$ & .59 \\
\hline 17 & $\begin{array}{l}\text { Participate in nursing research and/or implement research findings } \\
\text { appropriate to practice }\end{array}$ & .53 \\
\hline 25 & $\begin{array}{l}\text { Promote mutual peer support and collegial interactions to ensure } \\
\text { quality care and professional satisfaction }\end{array}$ & .50 \\
\hline 27 & Engage in consultation/collaboration to provide optimal care & .31 \\
\hline \multicolumn{3}{|c|}{ Factor 3: Professionalism (3.9\% variance, Cronbach's alpha $=.799)$} \\
\hline 6 & Establish standards as a guide for practice & .67 \\
\hline 7 & $\begin{array}{l}\text { Promote and maintain standards where planned learning activities for } \\
\text { students take place }\end{array}$ & .63 \\
\hline 5 & Participate in peer review & .62 \\
\hline 8 & Initiate actions to improve environments of practice & .58 \\
\hline 1 & Engage in ongoing self-evaluation & .53 \\
\hline 9 & Seek additional education to update knowledge and skills to maintain & .52 \\
\hline 4 & Assume responsibility for personal well-being & .44 \\
\hline 28 & Recognize professional boundaries & .31 \\
\hline
\end{tabular}




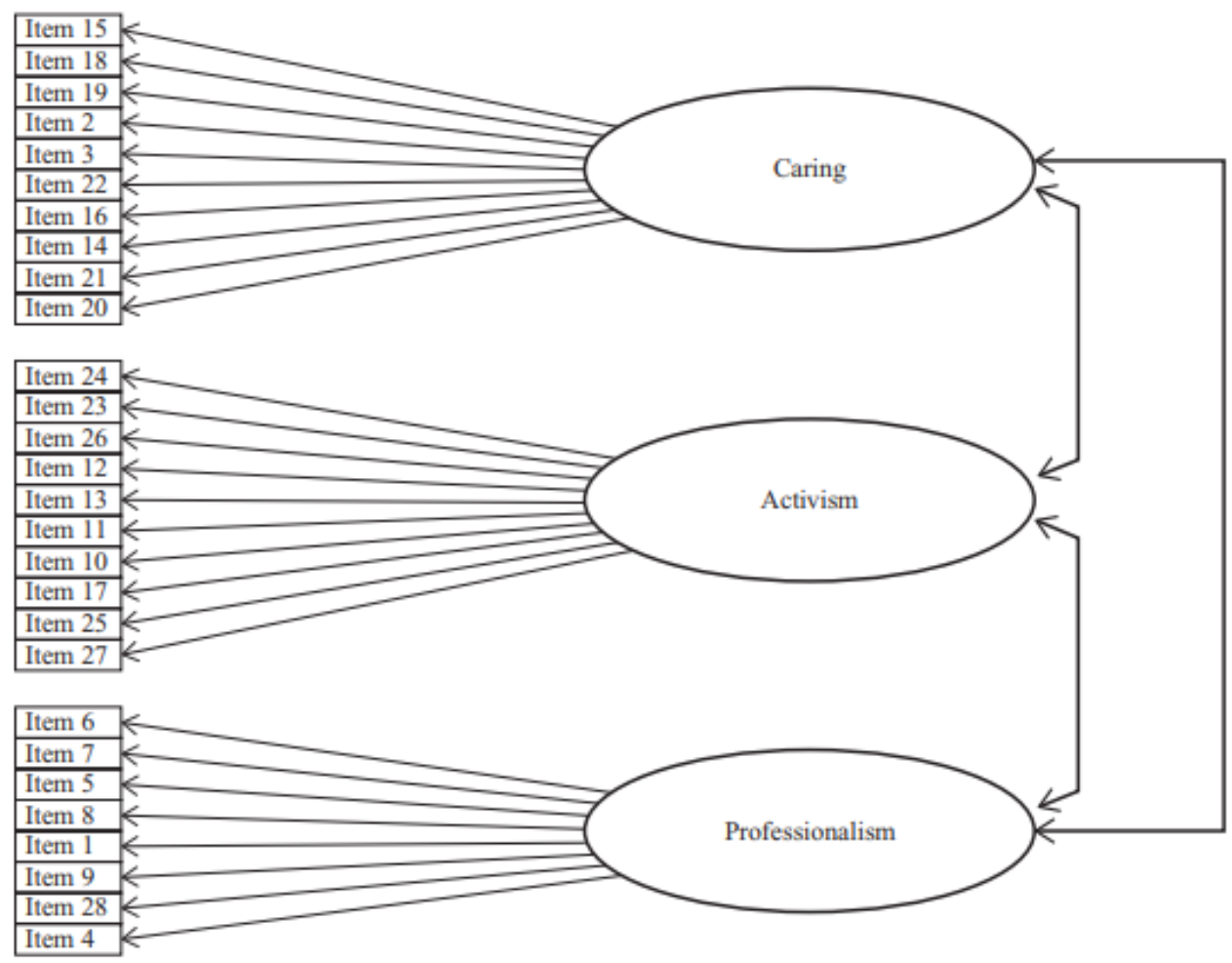

Figure 1. Confirmatory factor analysis of the Nurses Professional Values Scale-3 $(N=1,139)$.

\section{Reliability Assessment}

Cronbach's alpha for the instrument was .944. Deletion of a nonloading item had minimal effect and resulted in a Cronbach's alpha of .942 for the total scale. Cronbach's alpha for Factor 1 was .885; Factor 25 .912, and Factor 35.799 (see Table 1).

\section{DISCUSSION}

Psychometric evaluation of the 28-item NPVS-3, derived from the Code of Ethics for Nurses With Interpretive Statements (ANA, 2015), differs from the NPVS-R (Weis \& Schank, 2009), which was based on the 2001 Code for Ethics for Nurses. The 2015 Code of Ethics for Nurses reflects the changing boundaries as well as the increasing global concerns of nursing. These changes necessitated a reconceptualization and resulted in the new instrument, the NPVS-3. The revision of the NPVS-3 resulted in three factors, a change from the five-factor NPVS-R instrument. CFA supported the a priori three-factor structure developed from the conceptual model. The three factors are named Caring, Activism, and Professionalism. The goodness-of-fit indices approached an adequate level.

In the NPVS-3, Caring, the first factor, accounted for the greatest variance in professional values (39.9\%). The concept of caring is central to nursing practice and is inherent in the first three code provisions. These provisions deal with commitment to patient whether an individual, family or population, personal health, protection of patient health, and nursing practice without bias (Table 2). The notion of community/population is new to this Code of Ethics. Two items that loaded on Factor 1 may be found in two places in the new Code of Ethics. The first item, principles of fidelity and respect for 
person as well as the second item, responsibility and accountability for practice, can be found in the first group of provisions as well as the second group of provisions.

TABLE 2. Brief Overview of Provisions in the $\mathbf{2 0 1 5}$ American Nurses Association Code of Ethics

\begin{tabular}{l} 
Provisions \\
\hline 1. Respect the worth and dignity of all; nature of health and right to self-determination \\
2. Commitment to patient/populations; collaborative partnerships \\
3. Act as patient advocate; performance standards and safety \\
4. Authority, accountability and responsibility for nursing actions; promote health and \\
quality care \\
5. Personal responsibility for personal/professional self \\
6. Environment conducive to safe, high-quality conditions for patients and staff \\
7. Advancement of profession through research, standard development, and policy \\
8. Health diplomacy for human rights \\
9. Responsibility of professional nursing organizations for impacting global health \\
policy
\end{tabular}

Activism, the second factor, accounted for $7.8 \%$ of the variance. The last three provisions of the code address aspects of duties beyond individual patient encounters, reflecting the activist role of the nursing professional (see Table 2). These provisions focus on the social nature of the profession and its responsibility to the public and the global community. Although the world faces different health challenges, there are common health issues shared by people throughout the world. The protection and promotion of health among peoples regardless of locale is a concern of nursing. Not noted in previous Code of Ethics and accounting for changes in the items of the NPVS-3 are the right to health, civil rights, and human rights. There is also emphasis on fundamental freedoms, a global awareness of the human condition, including environmental and social justice concerns. The factor Activism encompasses these provisions. This factor includes the role of the profession in shaping public policy, professional efforts in advancing global health, reducing health disparities, participation in nursing associations, and contributing to research and scholarly inquiry. One item, promoting health of populations, which loaded on Activism, was also reflected in interpretive statements of the first three Code of Ethics provisions. Another item that loaded on Activism, peer support and collegial interactions, is reflected in interpretive statements in the second grouping of Code of Ethics provisions as well.

The third factor, called Professionalism, accounted for 3.9\% of the variance. This factor addresses fourth through sixth provisions of the code that focus on boundaries of duty and loyalty. These provisions include the nurses' authority, accountability and responsibility for nursing practice, leadership in promoting health, duty for personal and professional growth and well-being, and duty to provide ethical and quality care in a safe environment (see Table 2). Two items that loaded on Factor 2 are found in the new Code of Ethics in both the second and third grouping of provisions. The first item, the establishment of standards, is found in both the second and third group of provisions, and the second item, maintain standards for student learning, is also found in both the second and third group of provisions. Several interpretive statements in Code of Ethics (ANA, 2015) appear to have conceptual overlap and perhaps some redundancy which was not evidenced in previous Code of Ethics. Although the Code of Ethics provisions appear to be separate and distinct, the interpretive statements appear to 
have some redundancy which may be because of lack of conceptual clarity. This could explain why several items in the instrument are reflected in more than one grouping of code provisions.

In conclusion, initial testing of the NPVS-3 showed adequate levels of reliability and validity. However, the instrument warrants further testing and use with culturally diverse populations. The NPVS-3 could be used as a preintervention or screening instrument, for a postintervention evaluation tool for programs, targeting development of professional nursing values, and for assessment of professional nursing values over time.

\section{RELEVANCE TO NURSING EDUCATION, PRACTICE, OR RESEARCH}

Use of the NPVS-3 can raise consciousness about the importance of professional values and the Code of Ethics for Nurses as cornerstones of professionalism. The NPVS, NPVS-R, and NPVS-3 are the only known instruments based on the Code of Ethics. The NPVS-R instrument has been used by educators, master's and doctoral students at the national and international level, as well as nursing administrators. Researchers in many countries have adapted the NPVS-R instrument for culture and language.

\section{REFERENCES}

American Academy of Nursing. (2010). Implementing health care reform: Issues for nursing. Retrieved from http://www.aannet.org/assets/docs/implementinghealthcarereform.pdf

American Association of Colleges of Nursing. (2006). The essentials of doctoral education for advanced nursing practice. Washington, DC: Author.

American Association of Colleges of Nursing. (2008). The essentials of baccalaureate education for professional nursing practice. Washington, DC: Author.

American Association of Colleges of Nursing. (2011). The essentials of master's education in nursing. Washington, DC: Author.

American Nurses Association. (1985). Code of ethics for nurses with interpretive statements. Springfield, MD: Author.

American Nurses Association. (1998). Standards of clinical nursing practice (2nd ed.). Washington, DC: Author.

American Nurses Association. (2001). Code of ethics for nurses with interpretive statements. Washington, DC: Author.

American Nurses Association. (2010). Nursing's social policy statement: The essence of the profession. Silver Spring, MD: Author.

American Nurses Association. (2015). Code of ethics for nurses with interpretive statements. Washington, DC: Author.

Bentler P. M. (1997). EQS, a Structural Equation Program (Version 5.5) [Computer software]. Encino, CA: Multivariate Software.

Cattell R. B. (1978). The scientific use of factor analysis in behavioral and life sciences. New York, NY: Plenum Press.

Çelik S., \& Hisar F. (2012). The influence of the professionalism behaviour of nurses working in health institutions on job satisfaction. International Journal of Nursing Practice, 18(2), 180-187.

Cooper E. (2009). Creating a culture of professional development: A milestone pathway tool for registered nurses. Journal of Continuing Education in Nursing, 40(11), 501-508. 
Eddy D., Elfrink V., Weis D., \& Schank M. J. (1994). Importance of professional nursing values: A national study of baccalaureate programs. Journal of Nursing Education, 33, 257-262.

Ferketich S., \& Muller M. (1990). Factor analysis revisited. Nursing Research, 39, 59-62.

Field A. (2000). Discovering statistics using SPSS for Windows. London, United Kingdom: Sage.

Forbes M., \& Hickey M. (2009). Curriculum reform in baccalaureate nursing education: Review of the literature. International Journal of Nursing Education Scholarship, 6(1). 10.2202/1548923X.1797

Ham K. (2004). Principled thinking: A comparison of nursing students and experienced nurses. Journal of Continuing Education in Nursing, 35(2), 66-73.

Hu L., \& Bentler P. M. (1999). Cutoff criteria for fit indexes in covariance structure analysis: Conventional criteria versus new alternatives. Structural Equation Modeling, 6(1), 1-55.

Irving J., \& Snider J. (2002). Preserving professional values. Journal of Professional Nursing, 18(1), 5.

Krathwohl D., Bloom B., \& Masia B. (1964). Taxonomy of educational objectives, handbook II: Affective domain. New York, NY: David McKay.

LeDuc K., \& Kotzer A. (2009). Bridging the gap: A comparison of the professional nursing values of students, new graduates, and seasoned professionals. Nursing Education Perspectives, 30(5), 279-284.

Leners D. W., Roehrs C., \& Piccone A. V. (2006). Tracking the development of professional values in undergraduate nursing students. Journal of Nursing Education, 45, 504-511.

Lin Y., Wang L., Yarbrough S., Alfred D., \& Martin P. (2010). Changes in Taiwanese nursing student values during the educational experience. Nursing Ethics, 17(5), 646-654.

Lui M., Lam L. W., Lee I., Chien W., Chau J., \& Ip W. (2008). Professional nursing values among baccalaureate nursing students in Hong Kong. Nursing Education Today, 28(1), 108-114.

Lutz E., Elfrink V., \& Eddy D. (1991). Research on values and values education. In P. Baj \& G. Clayton (Eds.), Review of research in nursing education (Vol. 4, pp. 107-139). New York, NY: National League for Nursing.

Martin P., Yarbrough S., \& Alfred D. (2003). Professional values held by baccalaureate and associate degree nursing students. Journal of Nursing Scholarship, 35(3), 291-296.

McNeese-Smith D., \& Crook M. (2003). Nursing values and a changing nurse workforce: Values, age, and job stages. Journal of Nursing Administration, 33(5), 260-270.

Meyers L., Gamst G., \& Guarino A. J. (2006). Applied multivariate research: Design and interpretation. Thousand Oaks, CA: Sage.

Milton C. (2003). The American Nurses Association Code of Ethics: A reflection on the ethics of respect and human dignity with nurse as expert. Nursing Science Quarterly, 16(4), 301-304.

Nunnally J. C., \& Bernstein I. (1994). Psychometric theory (3rd ed.). New York, NY: McGraw-Hill.

O'Neill M. (1973). A study of baccalaureate nursing student values. Nursing Research, 22, 437-443.

Packard J., \& Ferrara M. (1988). In search of the moral foundation of nursing. ANS. Advances in Nursing Science, 10(4), 60-71.

Partridge K. B. (1978). Nursing values in a changing society. Nursing Outlook, 26, 356-360.

Rassin M. (2008). Nurses' professional and personal values. Nursing Ethics, 15(5), 614-630.

Raths L., Harmin M., \& Simon S. (1966). Values and teaching. Columbus, OH: Charles E. Merrill.

Schank M., \& Weis D. (2001). Service and education share responsibility for nurses' value development. Journal for Nurses in Staff Development, 17(5), 226-233. 
Sellman D. (2011). Professional values and nursing. Medicine, Health Care, and Philosophy, 14(2), 203208.

Shih F., Lin Y., Smith M., Liou Y., Chiang H., Lee S., \& Gau M. (2009). Perspectives on professional values among nurses in Taiwan. Journal of Clinical Nursing, 18(10), 1480-1489.

Strasen L. (1989). Values and vision in chaotic times. Journal of Nursing Administration, 19(3), 4-5, 25.

Strickland O. (2003). Using factor analysis for validity assessment: Practical considerations. Journal of Nursing Measurement, 11, 203-205.

Thorpe K., \& Loo R. (2003). The values profile of nursing undergraduate students: Implications for education and professional development. Journal of Nursing Education, 42(2), 83-90.

Thurston H. I., Flood M. A., Shupe I. S., \& Gerald K. B. (1989). Values held by nursing faculty and students in a university setting. Journal of Professional Nursing, 5(4), 199-207.

Weis D. (1995). Challenging our values: Directing health care reform. Nursing Policy Forum, 1, 22-26.

Weis D., \& Schank M. J. (2000). An instrument to measure professional nursing values. Journal of Nursing Scholarship, 32(2), 201-204.

Weis D., \& Schank M. J. (2002). Professional values: Key to professional development. Journal of Professional Nursing, 18(5), 271-275.

Weis D., \& Schank M. J. (2009). Development and psychometric evaluation of the Nurses Professional Values Scale-Revised. Journal of Nursing Measurement, 17(3), 221-231. 